\title{
Enhancing the Yields of Phenolic Compounds during Fermentation Using Saccharomyces cerevisiae Strain 96581
}

\author{
Adam A. Banach, Beng Guat Ooi* \\ Department of Chemistry, Middle Tennessee State University, Murfreesboro, TN, USA \\ Email: "Beng.Ooi@mtsu.edu
}

Received 2 September 2014; revised 28 September 2014; accepted 15 October 2014

Copyright (C) 2014 by authors and Scientific Research Publishing Inc.

This work is licensed under the Creative Commons Attribution International License (CC BY). http://creativecommons.org/licenses/by/4.0/

c) (i) Open Access

\section{Abstract}

Phenylethanol, tyrosol, and tryptophol are phenolic compounds or fusel alcohols formed via the Ehrlich pathway by yeast metabolism. These compounds can yield health benefits as well as contribute to the flavors and aromas of fermented food and beverages. This research shows that Saccharomyces cerevisiae Strain 96581 is capable of producing significantly higher levels of these three compounds when the precursor amino acids were supplemented into either the Chardonnay concentrate for wine-making or the malt concentrate for brewing English Ale. Strain 96581 can produce phenylethanol, tyrosol, and tryptophol as high as $434 \mathrm{mg} / \mathrm{kg}, 365 \mathrm{mg} / \mathrm{kg}$, and $129 \mathrm{mg} / \mathrm{kg}$, respectively, in the beer fermentation. The performance of Ale yeast WLP002 from White Labs Inc. was also analyzed for comparison. Strain 96581 outperformed WLP002 in the control beer, the amino acids supplemented beer, and the kiwi-beer background. This shows that Strain 96581 is more effective than WLP002 in converting the malt and the kiwi fruit supplements via its endogenous enzymes.

\section{Keywords}

Phenolic Antioxidants, Tyrosol, Tryptophol, Phenylethanol, Fermentation Technology

\section{Introduction}

Saccharomyces cerevisiae Strain 96581 isolated from spent liquor sulfite drums of pulp-making process was found to produce high amounts of fusel alcohols such as tyrosol, tryptophol, phenylethanol [1] [2]. These phenolic compounds have significant applications in food and beverage manufacturing including wine-making. Ty-

*Corresponding author.

How to cite this paper: Banach, A.A. and Ooi, B.G. (2014) Enhancing the Yields of Phenolic Compounds during Fermentation Using Saccharomyces cerevisiae Strain 96581. Food and Nutrition Sciences, 5, 2063-2070.

http://dx.doi.org/10.4236/fns.2014.521218 
rosol, found abundantly in olive oil, is a natural phenolic compound known to have high anti-oxidative properties [3] [4]. Samuel et al. [5] observed that tyrosol treatment in animals significantly reduced heart cell death as a result of protective signaling from Akt, eNOS, FOXO3a, and induced expression of the longevity protein SIRT1 in the heart. This suggests that tyrosol induces myocardial protection against ischemia-related stress by inducing survival and longevity proteins that may be considered as anti-aging therapy for the heart. Similarly, white wine has been reported as having cardioprotective benefits due to the presence of components such as tyrosol and caffeic acids that are believed to not only modulate oxidative stress and inflammation but also activate the cell survival signaling pathway and the FOXO3a longevity associated gene [6] [7].

It is known that tryptophol has a sleep-inducing property similar to the effects of serotonin or melatonin. Tryptophol present in wine and beer as byproducts of fermentation can also be produced in the human liver after disulfiram treatment for chronic alcoholism [8]. The synthesis of tryptophol by yeast was first described by Felix Ehrlich in 1912 [9] as the metabolic conversion of amino acids via the successive steps of transamination, decarboxylation, and reduction [10]. Tryptophol is also used as a precursor in the synthesis of the drug Indoramin, which is used commonly in many applications as an alpha blocker for cardiovascular diseases and high blood pressure treatment [11]. Phenylethanol is an aromatic compound that is commonly found in plants such as rose, carnation and orange blossom. It has a pleasant floral odor which makes it desirable in flavors and perfumes, particularly when the rose smell is desired. Due to its preservative properties, phenylethanol is often used in soap because of its stability in basic conditions. This can allow phenylethanol to act as a natural preservative in wine and beer to prevent spoilage. Phenylethanol has biological applications due to its antimicrobial properties. For example, it is produced by the fungus Candida albicans as an autoantibiotic [12].

Like wine, beer contains carbohydrates, amino acids, minerals, vitamins, and phenolic compounds. Many of these phenolic components have been identified as chemopreventive agents, antioxidants, cytochrome P450 1A inhibitors, detoxification enhancers, and anti-inflammatory agents through inhibition of the inducible nitric oxide synthase (iNOS) and the cyclooxygenase I (Cox-1) enzymes. Other potential benefits include estrogenic/anti-estrogenic properties, anti-proliferative and differentiation-inducing mechanisms, anti-angiogenic and anti-viral activities [13]-[16].

Wine and beer also contains flavonoids or polyphenolic compounds, which have potential health benefits such as antiviral, anti-allergic, antiplatelet, anti-inflammatory, antitumor and antioxidant activities. The flavonoid xanthohumol in beer is from the hop whereas the flavonoids in wine are mainly from the fruit. The fruit and the malt are also sources of amino acids. Natural fruit supplements were evaluated for possible application in beer production. Kiwi fruit and banana were among the fruits with the highest amounts of reported tyrosine, while grapes and apples were among the lowest [17]. The purpose of this study is to investigate the possibility of increasing the yield of tyrosol, tryptophol, and phenylethanol in fermentable beverages using two different yeast strains and supplementing the fermentable substrate with the relevant amino acid precursors or fruits high in these amino acids. In addition, the S. cerevisiae Strain 96581, which has never been classified as a wine or a beer strain, was tested for its ability to enhance the yields of the three phenolic compounds in both types of the fermentable media.

\section{Materials and Methods}

\subsection{Yeast Strains}

The yeast strains used in this study were the Saccharomyces cerevisiae ATCC Number 96581 from the American Type Culture Collection, [1] [2] and the English Ale yeast WLP-002 from the White Labs (Nashville, TN).

\subsection{Wine Fermentation}

The wine fermentation media was prepared with Alexander's Pinot Chardonnay grape juice concentrate (Grape and Granary, Akron, OH, USA) containing sulfite diluted to $16 \%$ (w/v) sugar content, minimal media of $0.67 \%$ Difco yeast nitrogen base without amino acids (Voigt Global Distribution, Lawrence, KS, USA), and with either one amino acid supplement i.e. tyrosine, tryptophan, phenylalanine added to each flask or all three amino acids (TTPaa) added at final concentrations of $0.05 \mathrm{mg} / \mathrm{mL}, 0.02 \mathrm{mg} / \mathrm{mL}, 0.05 \mathrm{mg} / \mathrm{mL}$ respectively into $50 \mathrm{~mL}$ final volume. Also included was the TTPaa NH4 which contained the fermentation media with 3 amino acid supplements plus $0.89 \mathrm{mg} / \mathrm{mL}$ yeast-nutrient-ammonium phosphate salt (Grape and Granary, Akron, OH, USA). The 
two controls were the fermentation media without amino acid supplements and the fermentation media with no amino acid supplements but contained $0.89 \mathrm{mg} / \mathrm{mL}$ yeast-nutrient-ammonium phosphate salt.

Overnight pre-inoculum cultures in YEPD (1\% yeast extract, $2 \%$ peptone, $2 \%$ dextrose) were incubated in a Barnstead Lab-line MaxQ 4000 incubator at $28^{\circ} \mathrm{C}$ with shaking at $200 \mathrm{rpm}$ and the optical density (OD) of the culture was determined at the wavelength of $600 \mathrm{~nm}$ using a Hitachi U-2000 UV-Vis spectrophotometer. Each aliquot of the $50 \mathrm{~mL}$ fermentable media was inoculated with $6.0 \times 10^{8}$ cells based on the conversion factor of 0.50 OD being equal to $1.0 \times 10^{7}$ cells. The flasks were topped with an air lock filled with sterile water to the point where no exchange with ambient air occurred. The cultures were kept in a Barnstead Lab-line MaxQ 4000 incubator at $18^{\circ} \mathrm{C}$ for 16 days (stirring twice daily). The fermentation was carried out in triplicate sets of experiments.

\subsection{Beer Fermentation}

The beer fermentation media was prepared using a modification of the English Ale recipe composed of chocolate malt barley grain, dried malt extract or DME and liquid malt extract or LME, supplemented with either the equivalent volume of Malt-kiwi purée or with amino acids. The chocolate malt barley grain (Dimgemams, Belgium), plain light Sparymalt dried extract (Muntons, England) and light barley malt liquid extract (Muntons, England) were purchased from All Seasons Brewing Supply (Nashville, TN). The Malt-DME-LME stock concentrate was prepared by steeping 17.97 grams of crushed chocolate malt barley grain in $600 \mathrm{~mL}$ water at $50^{\circ} \mathrm{C}$ for 1 hour, after which 119.8 grams DME powder and 395.5 grams of LME was added and the mixture boiled for 1 hour with continuous stirring. The entire mixture was reconstituted into a final volume of 1 liter. The "Malt only" stock, which contained only 2.995 grams of crushed barley grain in $500 \mathrm{~mL}$ water, was prepared the same way. The Malt-kiwi mixture was prepared using the 2.995 grams of crushed barley grain plus $446 \mathrm{~mL}$ of kiwi purée from 8 fruits in a final volume of $500 \mathrm{~mL}$. This mixture was also steeped at $50^{\circ} \mathrm{C}$ for 1 hour before boiling for 1 hour with stirring.

The fermentation samples consisted of a flask with the 5-fold diluted Malt-DME-LME stock medium supplemented with tyrosine, tryptophan, and phenylalanine at final concentrations of $0.05 \mathrm{mg} / \mathrm{mL}, 0.02 \mathrm{mg} / \mathrm{mL}$, $0.05 \mathrm{mg} / \mathrm{mL}$, respectively, in a final volume of $50 \mathrm{~mL}$ and a flask containing 1:1 volume ratio of the 5-fold diluted Malt-DME-LME stock to Malt-kiwi mixture. The controls were 1) a flask containing only the 5-fold diluted Malt-DME-LME stock medium without the amino acids supplement, and 2) a flask containing 1:1 volume ratio of the 5-fold diluted Malt-DME-LME and "Malt only" stock (i.e. No Kiwi). Each aliquot of the $50 \mathrm{~mL}$ fermentable media was inoculated with $6.0 \times 10^{8}$ cells from an overnight pre-inoculum. The cultures were kept under an anaerobic condition in a Barnstead Lab-line MaxQ 4000 incubator at $18^{\circ} \mathrm{C}$ for 14 days (stirring twice daily). The fermentation was carried out in triplicate sets of experiments.

\subsection{Sample Preparation and GC-MS Analysis}

The amount of glucose left in the fermentation was determined using the Clinitest kit (Fisher Scientific, Fairlawn, NJ, USA). The fermentation was considered complete if the glucose level in the culture dropped to less than $1 \%$, which then required the removal of cells by centrifugation. Exactly $20 \mathrm{~mL}$ aliquots of the supernatant were extracted with Merck Li Chrolut EN cartridges with $200 \mathrm{mg}$ resin each (purchased from VWR International, West Chester, PA, USA) using a modified solid-phase extraction procedure described by Ooi et al. [2]. For the quantitation of selected fermentation components and for monitoring the consistency of the SPE extraction, a $60 \mu \mathrm{L}$ standard solution containing $1000 \mathrm{ppm}$ (w/w) of d5-deuterated-phenethyl alcohol (Isotec, Sigma-Aldrich, St. Louis, MO, USA) in ethanol (Pharmaco Inc., Brookfield, CT, USA) was added to $20 \mathrm{~mL}$ of the fermentation samples as an internal standard before being loaded onto the SPE cartridges for elution. Sample extracts were eluted from the LiChrolut EN twice with $1.0 \mathrm{~mL}$ of 1:1 volume mixture of dichloromethane (Sigma-Aldrich, St. Louis, MO, USA) and methanol (HPLC grade, Fisher Scientific, Fairlawn, NJ, USA). The eluate was filtered through a syringe filter (Pall Life Sciences, Ann Arbor, MI, USA) of $0.22 \mu \mathrm{m}$ pore size and $13 \mathrm{~mm}$ diameter and diluted 1 to 10 fold or 1 to 5 fold in a dichloromethane: methanol (1:1) solvent mixture for GC-MS analysis. Analysis of fermentation components were carried out using the Shimadzu QP2010 S GC-MS equipped with a Phenomenex ZB5-HT, 30-m column with $0.25 \mathrm{~mm}$ i.d. and $0.25 \mu \mathrm{m}$ film thickness. The temperature program used had an initial temperature of $40^{\circ} \mathrm{C}$ for 2 minutes followed by a heating rate of $12^{\circ} \mathrm{C} / \mathrm{min}$ to reach to $140^{\circ} \mathrm{C}$, which was held for $1 \mathrm{~min}$ and then increased at $20^{\circ} \mathrm{C} / \mathrm{min}$ to $300^{\circ} \mathrm{C}$ with a final hold period of 4 minutes. A he- 
lium carrier gas flow rate of $1.23 \mathrm{~mL} / \mathrm{min}$ and split injection mode with split ratio of 1:10 was used for GC analysis of a sample size of $1 \mu \mathrm{L}$. GC-MS analyses were repeated three times for triplicate batches of fermentation from each strain.

\subsection{Calibration and Statistical Analysis}

The concentrations (mg $\mathrm{kg}^{-1}$ or ppm) reported in this paper were calculated using external standard calibration. A standard stock solution containing $1000 \mathrm{ppm}(\mathrm{w} / \mathrm{w}$ ) each of 2-phenethyl alcohol, 4-hydroxyphenethyl alcohol (4-hydroxy-benzeneethanol or tyrosol), 3-indoleethanol (tryptophol) and d5(ring)-phenethyl alcohol (D5) purchased from Sigma-Aldrich, St. Louis, MO, USA were prepared in the dichloromethane-methanol solvent mixture. Serial dilutions of this multicomponent standard were carried out for quantitative analysis. The mean values with standard deviations (SD) are reported. The beer fermentation data from this study was statistically analyzed using the general linear model (GLM) Multivariate Analysis of Variance (MANOVA; SAS 9.3 from the SAS Institute Inc.). The GLM-MANOVA approach was used to test the hypothesis of the significance association between a set of interrelated dependent variables (concentrations of phenolic compounds) and two grouping variables. A univariate analysis was performed to establish whether the supplements and yeast strains were associated significantly with any of the phenolic yields. The Wilks' Lambda technique was used to test the impact of each variable included in the multivariate model on the phenolics. The null hypotheses of no overall statistical significance of yeast strain influence on the yield of the three phenolic compounds and of no overall difference in yields from the amino acids and kiwi supplemented beer fermentation among the two yeast strains was carried out using the MANOVA test criteria at the significance level or " $\alpha$ value" of $\mathrm{P}<0.05$. The subsequent one-way ANOVA test criteria at the significance levels or $\mathrm{P}<0.05$ was performed to determine whether the yeast strain has a significant influence on tyrosol, tryptophol, and phenylethanol production and whether the sample media have a significant effect on the production of each type of phenolic compound [18].

\section{Results and Discussion}

There was a significant increase in phenylethanol, tyrosol, and tryptophol, when wine fermentation was supplemented with phenylalanine, tyrosine, or tryptophan respectively. The increase in the production of tryptophol by the 96581 strain when tryptophan was supplemented in the media was in the order of 7 to 8-fold and 2-fold for phenylethanol and tyrosol. If all three amino acids were supplemented, then there was increase in all three fusel alcohols as in the fermentation samples labeled as TTPaa (Figure 1). The TTPaa sample plus the yeast nutrient ammonium phosphate salt (TTPaa NH4) showed about the same level of increase in yield over the TTPaa sample without added ammonium phosphate salts, suggesting that the additional ammonium phosphate salts were not essential for enhancing the synthesis of fusel alcohols from their amino acid precursors.

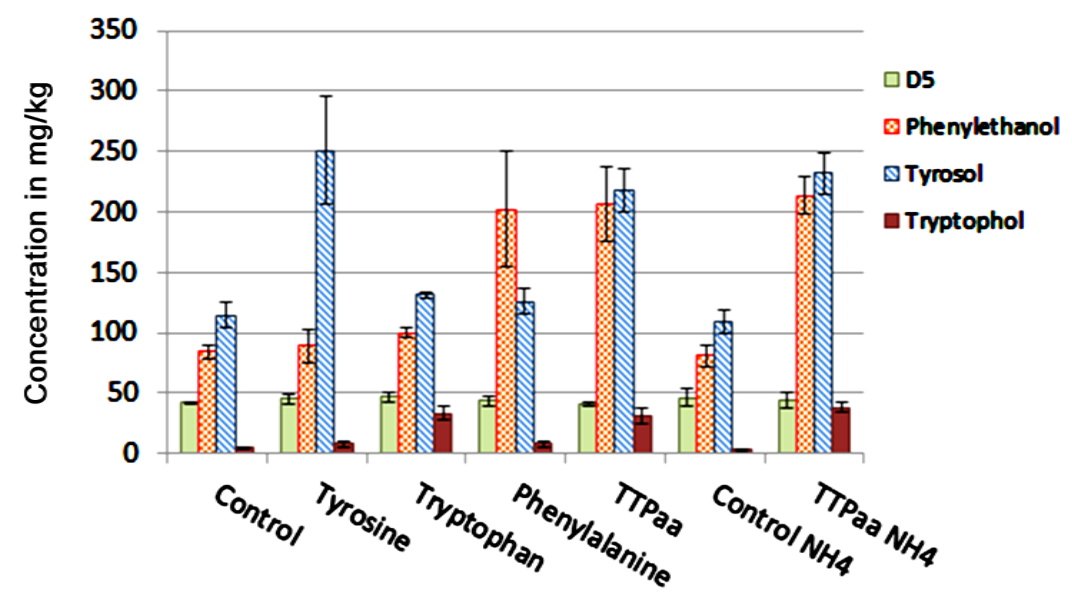

Figure 1. Concentration levels of phenylethanol, tyrosol, and tryptophol produced in wine fermentation. Fermentation was carried out using yeast Stain 96581. Amino acids supplements are indicated on the x-axis. TTPaa stands for the amino acids tyrosine, tryptophan, and phenylalanine supplements in the media. $\mathrm{NH}_{4}$ indicates that $0.89 \mathrm{mg} / \mathrm{mL}$ of yeast-nutrient-ammonium phosphate salt had been added to the media. D5 is the d5-deuterated-phenylethanol. 
In the control beer fermentation, Strain 96581 produced more fusel alcohol than the English Ale yeast strain WLP002. When supplemented with all three amino acids precursors both strains were able to increase production of all three fusel alcohols. The total amounts of phenylethanol, tyrosol, and tryptophol produced by Strain 96581 were $434 \pm 90 \mathrm{mg} / \mathrm{kg}, 365 \pm 67 \mathrm{mg} / \mathrm{kg}$, and $129 \pm 32 \mathrm{mg} / \mathrm{kg}$, respectively. Strain WLP002 under the same fermentation conditions produced $307 \pm 2 \mathrm{mg} / \mathrm{kg}, 305 \pm 16 \mathrm{mg} / \mathrm{kg}$, and $110 \pm 6 \mathrm{mg} / \mathrm{kg}$, respectively (Figure 2 and Table 1). The higher yields of the three fusel alcohols in the control sample fermented by the 96581 strain

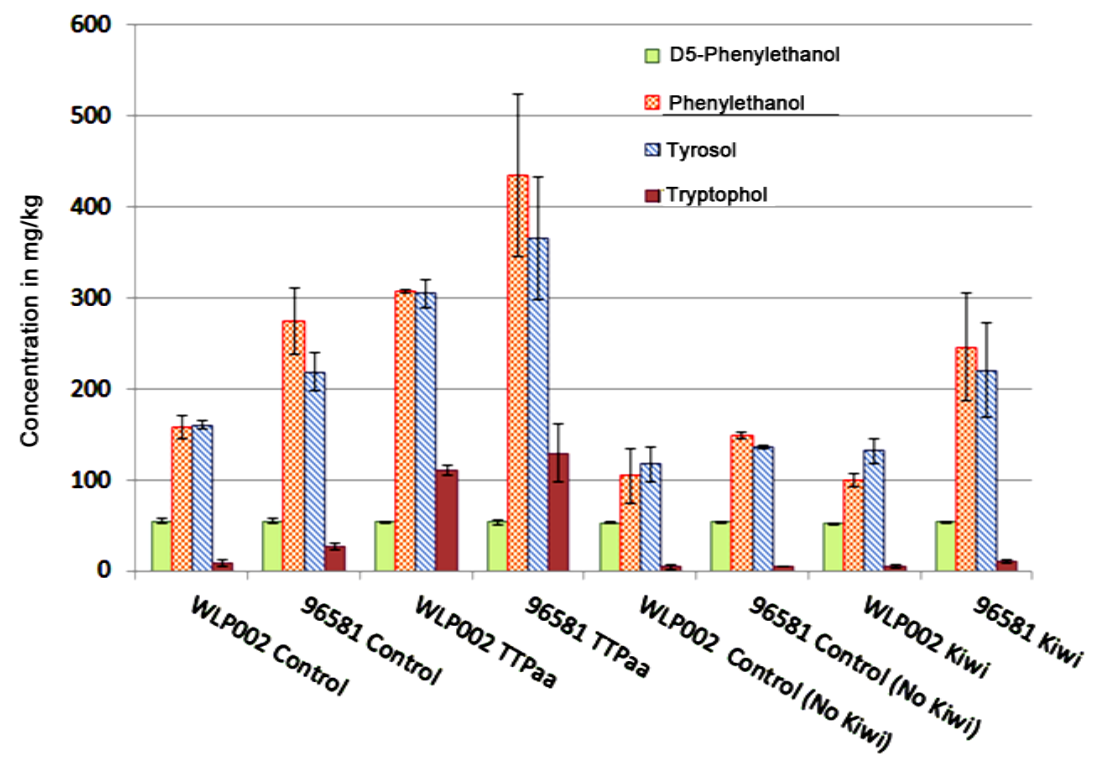

Figure 2. Concentration levels of phenylethanol, tyrosol, and tryptophol produced in beer fermentation. Fermentation was conducted using an ale yeast Strain WLP002 versus a non-beer yeast Strain 96581 for comparison. TTPaa stands for the amino acids tyrosine, tryptophan, and phenylalanine supplements in the media.

Table 1. Concentration of D5-phenylethanol, phenylethanol, tyrosol, and tryptophol in beer sample.

\begin{tabular}{ccccc}
\hline \multirow{2}{*}{ Strain } & \multicolumn{3}{c}{${ }^{\text {a }}$ Sample } \\
\cline { 2 - 4 } & D5 & Phenylethanol & Tyrosol & Tryptophol \\
\hline WLP002 Control & $54 \pm 3$ & $158 \pm 13$ & $160 \pm 5$ & $9.0 \pm 3.5$ \\
96581 Control & $54 \pm 3$ & $275 \pm 37$ & $219 \pm 21$ & $27 \pm 3$ \\
WLP002 TTPaa & $53 \pm 1$ & $307 \pm 2$ & $305 \pm 16$ & $110 \pm 6$ \\
96581 TTPaa & $54 \pm 3$ & $434 \pm 90$ & $365 \pm 67$ & $129 \pm 32$ \\
WLP002 Control (No Kiwi) & $52 \pm 1$ & $104 \pm 30$ & $117 \pm 20$ & $4.1 \pm 2.2$ \\
96581 Control (No Kiwi) & $53 \pm 1$ & $149 \pm 4$ & $136 \pm 2$ & $5.0 \pm 0.6$ \\
WLP002 Kiwi & $51 \pm 1$ & $100 \pm 7$ & $132 \pm 13$ & $4.1 \pm 2.0$ \\
96581 Kiwi & $53 \pm 1$ & $245 \pm 59$ & $220 \pm 52$ & $10 \pm 2$ \\
ANOVA F Value & & & & 5.15 \\
bStrain Effect & - & 40.26 & 46.28 & 132.92 \\
'Media Effect & - & 38.49 & 465 & \\
\hline
\end{tabular}

${ }^{a}$ All sample concentrations are given in $\mathrm{mg} / \mathrm{kg}$ units including their corresponding standard deviation values. Statistical calculation was performed for 0.05 level of statistical significance using the one-way ANOVA test and F values for the hypothesis of no effect of yeast strains and no effects of sample media on the concentration of phenylethanol, tyrosol, and tryptophol produced. F values are tabulated in the bottom two rows. ${ }^{\mathrm{b}}$ The significant effects of yeast strains are expressed as $\left(\mathrm{F}_{(1,16)}=40.26, \mathrm{P}<0.05, \mathrm{R}^{2}=0.91\right.$, $\left.\mathrm{MSE}=1753.5\right) ;\left(\mathrm{F}_{(1,16)}=18.28, \mathrm{P}<0.05, \mathrm{R}^{2}=0.91, \mathrm{MSE}=1049.4\right)$; $\left(F_{(1,16)}=5.15, P<0.05, R^{2}=0.96\right.$, MSE $\left.=138.1\right)$ for phenylethanol, tyrosol, and tryptophol, respectively. ${ }^{\mathrm{c}}$ The significant effects of sample media are expressed as $\left(\mathrm{F}_{(3,16)}=38.49, \mathrm{P}<0.05, \mathrm{R}^{2}=0.91\right.$, $\left.\mathrm{MSE}=1753.5\right) ;\left(\mathrm{F}_{(3,16)}=46.05, \mathrm{P}<0.05, \mathrm{R}^{2}=0.91, \mathrm{MSE}=1049.4\right) ;\left(\mathrm{F}_{(3,16)}=132.92, \mathrm{P}<0.05, \mathrm{R}^{2}=\right.$ $0.96, \mathrm{MSE}=138.1)$ for phenylethanol, tyrosol, and tryptophol, respectively. 
suggests that this strain is more effective than the WLP002 strain in utilizing the fermentable malt and malt sugar substrates. This could be attributed to the greater efficiency and/or higher levels of endogenous enzymes to help break down the malt precursors to produce the fusel alcohols in Strain 96581. The WLP002 strain, however, relies more on the supplemented amino acids.

The increased fusel alcohol production in beer by Strain 96581 can be attributed to its highly active and efficient Ehrlich pathway for utilizing nutrients from the fermentable substrate and allowing the yeast to grow and propagate more rapidly. The release of nutrients occurs during the malting process of the barley grain when the partially germinating grain produces specialized enzymes that break down starches and proteins into simple sugars and amino acids, respectively [19]. Researchers at the United States Agricultural Research Service found that the enzymes called serine-class proteases serve the dual purpose of digesting proteins in the grain into amino acids as well as degrading the beta-amylases, which are involved in the conversion of carbohydrates into simple sugars [20], creating an optimal balance between the amount of amino acids and sugars that would influence the malted barley flavor [21]. The availability of additional amino acids and basic sugars in the yeast culture medium allows for faster growth of the fermenting yeast as well as more efficient fusel alcohol production.

The rationale for using kiwi fruit as a fermentation substrate is related to the desirable aroma profile of the aqueous essence and fresh puree. About thirty aroma active components consisting of predominantly alcohols, ketones, and esters have been characterized by the multidimensional gas chromatography-olfactometry technique [22]. In this study, the addition of kiwi fruit purée resulted in about 1.6 to 2-fold increase in the levels of phenylethanol, tyrosol, and tryptophol produced by Strain 96581. However, there was no appreciable increase in the production of these alcohols by the English Ale WLP002 strain (Figure 2, Table 1). The 96581 strain apparently was able to utilize amino acid precursors and simple sugars derived from the kiwi fruits and produce more fusel alcohols. This characteristic was not observed for the English Ale yeast. The F values from the one-way ANOVA statistics for the formation of tyrosol, tryptophol, and phenylethanol shown on Table 1 further support the significance of nutrient supplements as well as the significant influence of yeast strains on the production of the three phenolic compounds. The multivariate analysis of variance also revealed that there is an overall significant influence of yeast strain on the production of tyrosol, tryptophol, and phenylethanol (Wilks' $\lambda=$ 0.1377, $\left.\mathrm{F}_{(3,14)}=29.23, \mathrm{P}<0.05\right)$ and a significant difference between control, TTPaa, No Kiwi control, and Kiwi samples on the production of the phenolic components (Wilks' $\lambda=0.0075, \mathrm{~F}_{(9,34)}=24.54, \mathrm{P}<0.05$ ).

Although phenylethanol may be considered a desirable constituent contributing to wine or beer flavor, high levels of tyrosol and tryptophol may not be desirable due to their bitter yeast bite and bitter almond taste, respectively. Yet, threshold levels as high as 200, 100, and $75 \mathrm{mg} /$ liter for tryptophol, tyrosol, and phenylethanol have been reported in the literature [23] [24] and it is known that ale drinkers prefer lager samples containing 8 times the original level of tryptophol [25]. Szlavko [25] has also shown that inherent differences in metabolic process among yeast strains, raw materials, fermentation media composition, and fermentation conditions can influence the level of each fusel alcohol formed. Despite the inhibitory effects of high levels of phenylethanol to yeast growth, the thermotolerant and multi-stress resistant strains of $S$. cerevisiae have been shown to produce levels of phenylethanol as high as $4.5 \mathrm{~g} /$ liter [26].

\section{Conclusion}

Wine and beer have been known to provide multiple health benefits when consumed in moderation. The goal of improving wine and beer quality with boosted amounts of fusel alcohols such as tyrosol, tryptophol and phenylethanol was to increase the antioxidant levels present in these alcoholic beverages for health benefits as well as enhancing the flavor of these alcoholic beverages. This study showed that the outcomes of flavor enhancement and enrichment of antioxidants could be achieved through supplementing the fermentation media with precursor amino acids as well as careful choices of the appropriate yeast strain. The 96581 strain outperformed the English Ale yeast WLP002 because it could utilize additional nutrients from the malt and kiwi for the production of fusel alcohols. Strain 96581 performed well in all three fermentable substrates for making wine, beer, and fruitsupplemented beer, making it an attractive candidate for commercial applications.

\section{Acknowledgements}

We thank Professor Jwa K. Kim from the Department of Psychology at Middle Tennessee State University and 
Ms. June Vichuda Hunter from the Department of Chemistry for performing the statistical data analysis of the beer samples.

\section{References}

[1] Linden, T., Peetre, J. and Hahn-Hagerdal, B. (1992) Isolation and Characterization of Acetic Acid-Tolerant Galactose-Fermenting Strains of Saccharomyces cerevisiae from a Spent Sulfite Liquor Fermentation Plant. Applied and Environmental Microbiology, 58, 1661-1669.

[2] Ooi, B.G., Wanamaker, L.E., Markuszewski, B.M. and Chong, N.S. (2008) Genetic and Enological Analysis of Selected Saccharomyces cerevisiae Strains for Wine Production. International Journal of Food Science and Technology, 43, 1111-1120. http://dx.doi.org/10.1111/j.1365-2621.2007.01577.x

[3] Giovannini, C., Straface, E., Modesti, D., Coni, E., Cantafora, A., De Vincenzi, M., Malorni, W. and Masella, R. (1999) Tyrosol, the Major Olive Oil Biophenol, Protects against Oxidized-LDL-Induced Injury in Caco-2 Cells. Journal of Nutrition, 129, 1269-1277.

[4] Miró-Casas, E., Covas, M., Fitó, M., Farré-Albadalejo, M., Marrugat, J. and de la Torre, R. (2003) Tyrosol and Hydroxytyrosol are Absorbed from Moderate and Sustained Doses of Virgin Olive Oil in Humans. European Journal of Clinical Nutrition, 57, 186-190. http://dx.doi.org/10.1038/sj.ejcn.1601532

[5] Samuel, S.M., Thirunavukkarasu, M., Penumathsa, S.V., Paul, D. and Maulik, N. (2008) Akt/FOXO3a/SIRT1-Mediated Cardioprotection by n-Tyrosolagainst Ischemic Stress in Rat in Vivo Model of Myocardial Infarction: Switching Gears toward Survival and Longevity. Journal of Agricultural Food Chemistry, 56, 9692-9698. http://dx.doi.org/10.1021/jf802050h

[6] Willcox, B.J., Donlon, T.A., He, Q., Chen, R., Grove, J.S., Yano, K., Masaki, K.H., Willcox, D.C, Rodriguez, B. and Curb, J.D. (2008) FOXO3a Genotype Is Strongly Associated with Human Longevity. Proceedings of the National Academy of Science of the United States of America, 105, 13987-13992. http://dx.doi.org/10.1073/pnas.0801030105

[7] Thirunavukkarasu, M., Penumathsa, S.V., Samuel, S.M., Akita, Y., Zhan, L., Bertelli, A.A., Maulik, G. and Maulik, N. (2008) White Wine-induced Cardio Protection against Ischemia-Reperfusion Injury is Mediated by Life-Extending Akt/FOXO3a/NF $\kappa$ B Survival Pathway. Journal of Agricultural and Food Chemistry, 56, 6733-6739. http://dx.doi.org/10.1021/jf801473v

[8] Cornford, E.M., Bocash, W.D., Braun, L.D., Crane, P.D., Oldendorf, W.H. and MacInnis, A.J. (1979) Rapid Distribution of Tryptophol (3-Indole Ethanol) to the Brain and Other Tissues. Journal of Clinical Investigation, 63, 1241-1248. http://dx.doi.org/10.1172/JCI109419

[9] Ehrlich, F. (1912) Uber Tryptophol ( $\beta$-Indolyl-Athylalkohol), Einneues Garprodukt der Hefeaus Aminosauren. Berichte der DeutschenChemischenGesellschaft, 45, 883-889. http://dx.doi.org/10.1002/cber.191204501134

[10] Hazelwood, L.A., Daran, J.-M., van Marris, A.J.A., Pronk, J.T. and Dickson, J.R. (2008) Ehrlich Pathway for Fusel Alcohol Production: A Century of Research on Saccharomyces cerevisiae Metabolism. Applied and Environmental Microbiology, 74, 2259-2266. http://dx.doi.org/10.1128/AEM.02625-07

[11] Holmes, B. and Sorkin, E.M. (1986) Indoramin. Drugs, 31, 467-499. http://dx.doi.org/10.2165/00003495-198631060-00002

[12] Lingappa, B.T., Prasad, M., Lingappa, Y., Hunt, D.F. and Biemann, K. (1969) Phenethyl Alcohol and Tryptophol: Autoantibiotics Produced by the Fungus Candida albicans. Science, 163, 192-194. http://dx.doi.org/10.1126/science.163.3863.192

[13] Jang, M., Cai, L., Udeani, G.O., Slowing, K.V., Thomas, C.F., Beecher, C.W., Fong, H.H., Farnsworth, N.R., Kinghown, A.D., Mehta, R.G., Moon, R.C. and Pezzuto, J.M. (1997) Cancer Chemopreventive Activity of Resveratrol, a Natural Product Derived from Grapes. Science, 275, 218-220. http://dx.doi.org/10.1126/science.275.5297.218

[14] Gerhäuser, C. (2005) Beer Constituents as Potential Cancer Chemopreventive Agents. European Journal of Cancer, 41, 1941-1954. http://dx.doi.org/10.1016/j.ejca.2005.04.012

[15] Zhao, F., Nozawa, H., Daikonnya, A., Kondo, K. and Kitanaka, S. (2003) Inhibitors of Nitric Oxide Production from Hops (Humulus lupulus L.) Biological \& Pharmaceutical Bulletin, 26, 61-65. http://dx.doi.org/10.1248/bpb.26.61

[16] Buckwold, V.E., Wilson, R.J., Nalca, A., Beer, B.B., Voss, T.G., Turpin, J.A., Buckheit, R.W., Wei, J., Wenzel-Mathers, M., Walton, E.M., Smith, R.J., Pallansch, M., Ward, P., Wells, J., Chuvala, L., Sloane, S., Paulman, R., Russell, J., Hartman, T. and Ptak, R. (2004) Antiviral Activity of Hop Constituents against a Series of DNA and RNA Viruses. Antiviral Research, 61, 57-62. http://dx.doi.org/10.1016/S0166-3542(03)00155-4

[17] Fruits High in Tyrosine. Whole Food Catalog. N.p. Web. http://wholefoodcatalog.info/nutrient/tyrosine/foods/high/15/

[18] Carey, G. (1998) Multivariate Analysis of Variance (MANOVA) II: Practical Guide to ANOVA and MANOVA for 
SAS. http://ibgwww.colorado.edu/ carey/p7291dir/handouts/manova2.pdf

[19] OSU (2014) Barley (Hordeum vulgare L.). Quality Factors for Malting, Brewing and Other End-Uses. http://oregonstate.edu/instruct/css/330/five/BarleyOverview.htm

[20] Wood, M. (2010) Secrets to Superb Malting Barleys Explored by ARS Researchers. USDA Agricultural Research Service. http://www.ars.usda.gov/is/pr/2010/100203.htm

[21] Wood, M. (2010) Like Malt? You'll Love This Malting Barley Research! USDA Agricultural Research Service. http://www.ars.usda.gov/is/ar/archive/feb10/malt0210.htm

[22] Jordán, M.J., Margaría, C.A., Shaw, P.E. and Goodner, K.L. (2002) Aroma Active Components in Aqueous Kiwi Fruit Essence and Kiwi Fruit Puree by GC-MS and Multidimensional GC/GC-O. Journal of Agriculture and Food Chemistry, 50, 5386-5390. http://dx.doi.org/10.1021/jf020297f

[23] Harrison, G.A.F. (1970) The Flavour of Beer-A Review. Journal of the Institute of Brewing, 76, 486-495. http://dx.doi.org/10.1002/j.2050-0416.1970.tb03333.x

[24] Rosculet, G. (1971) Aroma and Flavor of Beer. II. Origin and Nature of Less Volatile and Nonvolatile Components of Beer. The Brewers Digest, 46, 68-98.

[25] Szlavko, C.M. (1973) Tryptophol, Tyrosol and Phenylethanol—-The Aromatic Higher Alcohols in Beer. Journal of the Institute of Brewing, 79, 283-288.http://dx.doi.org/10.1002/j.2050-0416.1973.tb03541.x

[26] Eshkol, N., Sendovski, M., Bahalul, M., Katz-Ezov, T., Kashi, Y. and Fishman, A. (2009) Production of 2-Phenylethanol from L-Phenylalanine by a Stress Tolerant Saccharomyces cerevisiae Strain. Journal of Applied Microbiology, 2, 534-542. http://dx.doi.org/10.1111/j.1365-2672.2008.04023.x 
Scientific Research Publishing (SCIRP) is one of the largest Open Access journal publishers. It is currently publishing more than 200 open access, online, peer-reviewed journals covering a wide range of academic disciplines. SCIRP serves the worldwide academic communities and contributes to the progress and application of science with its publication.

Other selected journals from SCIRP are listed as below. Submit your manuscript to us via either submit@scirp.org or Online Submission Portal.
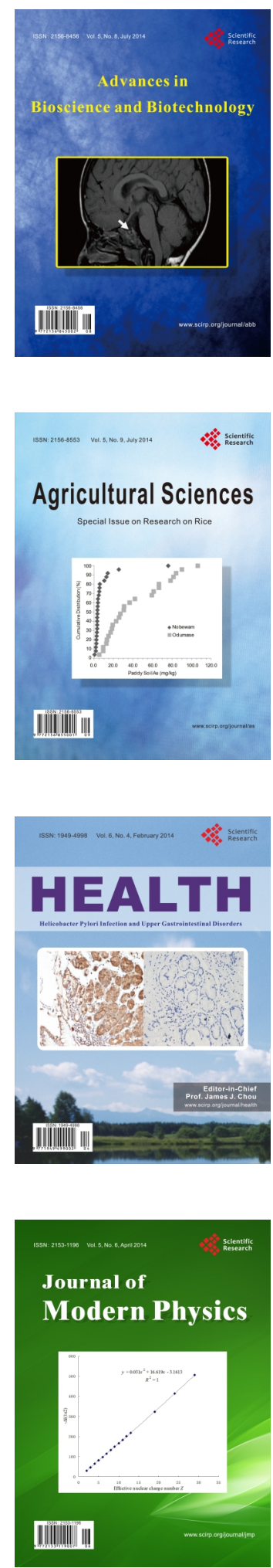
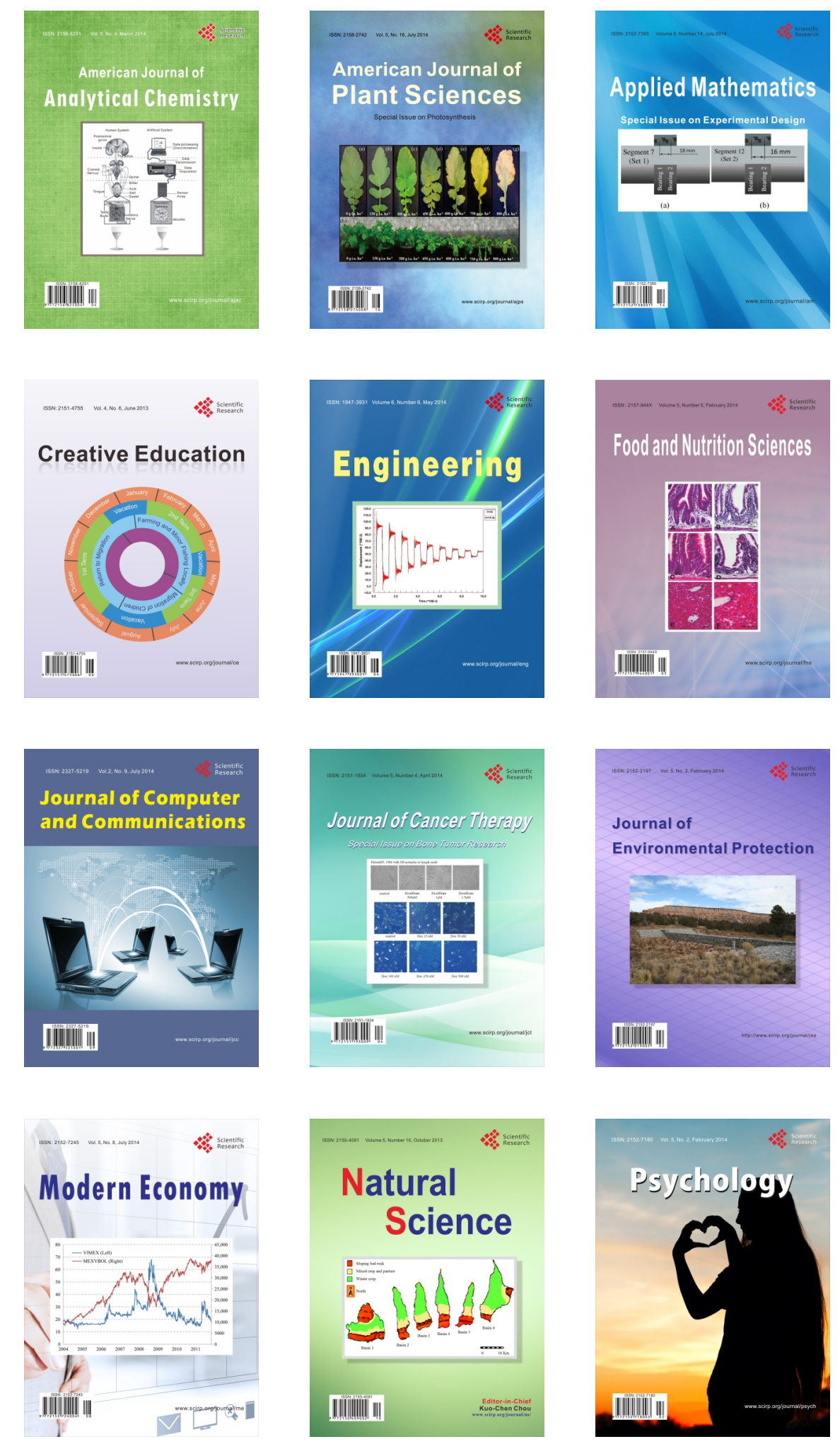